\title{
The Dbp5 cycle at the nuclear pore complex during mRNA export I: $d b p 5$ mutants with defects in RNA binding and ATP hydrolysis define key steps for Nup159 and Gle1
}

\author{
Christine A. Hodge, ${ }^{1}$ Elizabeth J. Tran, ${ }^{2,7}$ Kristen N. Noble, ${ }^{2,6}$ Abel R. Alcazar-Roman, ${ }^{2,8}$ \\ Rakefet Ben-Yishay, ${ }^{3,4}$ John J. Scarcelli, ${ }^{1,9}$ Andrew W. Folkmann, ${ }^{2}$ Yaron Shav-Tal, ${ }^{3,4}$ \\ Susan R. Wente, ${ }^{2}$ and Charles N. Cole ${ }^{1,5,10}$
}

${ }^{1}$ Department of Biochemistry, Dartmouth Medical School, Hanover, New Hampshire 03755, USA; ${ }^{2}$ Department of Cell and Developmental Biology, Vanderbilt University School of Medicine, Nashville, Tennessee 37232, USA; $^{3}$ The Mina and Everard Goodman Faculty of Life Sciences, Bar-Ilan University, Ramat Gan 52900, Israel; ${ }^{4}$ Institute of Nanotechnology, Bar-Ilan University, Ramat Gan 52900, Israel; ${ }^{5}$ Department of Genetics, Dartmouth Medical School, Hanover, New Hampshire 03755, USA; ${ }^{6}$ Department of Microbiology and Immumology, Meharry Medical College, Nashville, Tennessee 27208, USA

Nuclear export of messenger RNA (mRNA) occurs by translocation of mRNA/protein complexes (mRNPs) through nuclear pore complexes (NPCs). The DEAD-box protein Dbp5 mediates export by triggering removal of mRNP proteins in a spatially controlled manner. This requires Dbp5 interaction with Nup159 in NPC cytoplasmic filaments and activation of Dbp5's ATPase activity by Gle1 bound to inositol hexakisphosphate $\left(\mathrm{IP}_{6}\right)$. However, the precise sequence of events within this mechanism has not been fully defined. Here we analyze $d b p 5$ mutants that alter ATP binding, ATP hydrolysis, or RNA binding. We found that ATP binding and hydrolysis are required for efficient Dbp5 association with NPCs. Interestingly, mutants defective for RNA binding are dominant-negative (DN) for mRNA export in yeast and human cells. We show that the DN phenotype stems from competition with wild-type Dbp5 for Gle1 at NPCs. The Dbp5-Gle1 interaction is limiting for export and, importantly, can be independent of Nup159. Fluorescence recovery after photobleaching experiments in yeast show a very dynamic association between Dbp5 and NPCs, averaging $<1$ sec, similar to reported NPC translocation rates for mRNPs. This work reveals critical steps in the Gle1-IP 6 /Dbp5/Nup159 cycle, and suggests that the number of remodeling events mediated by a single Dbp5 is limited.

[Keywords: nucleocytoplasmic transport; DEAD-box proteins; nuclear pore complex; FRAP; dominant-negative mutants]

Supplemental material is available for this article.

Received February 14, 2011; revised version accepted April 1, 2011.

Messenger RNAs (mRNAs) are produced in the nucleus through a series of highly coordinated steps that include transcription, processing, and assembly with proteins to form a messenger ribonucleoprotein complex (mRNP) (for reviews, see Pandit et al. 2008; Zhong et al. 2009; Licatalosi and Darnell 2010). Some of the factors that participate in these steps associate with RNA polymerase II

Present addresses: ${ }^{7}$ Department of Biochemistry, Purdue University, $175 \mathrm{~S}$. University Street, West Lafayette, IN 47907, USA; ${ }^{8}$ Department of Cell Biology, Yale University, New Haven, CT 06511, USA; ${ }^{9}$ Tetragenetics, Inc., Cambridge, MA 02142, USA.

${ }^{10}$ Corresponding author.

E-MAIL charles.cole@dartmouth.edu; FAX (603) 650-1128.

Article is online at http://www.genesdev.org/cgi/doi/10.1101/gad.2041611. during transcription (Cho et al. 1997; Moore and Proudfoot 2009; Perales and Bentley 2009), facilitating coordination by positioning these factors to interact with nascent RNAs upon recognition of key sequence elements or structures. This results in the formation of mRNPs that are exported to the cytoplasm for translation after premRNA processing has been completed.

mRNPs are exported through nuclear pore complexes (NPCs), large macromolecular structures (>60 MDa) embedded in the nuclear envelope (NE) (for reviews, see D'Angelo and Hetzer 2008; Hetzer and Wente 2009; Wente and Rout 2010). NPCs have eightfold radial symmetry perpendicular to the NE plane, and the NPC core has twofold symmetry in the NE plane. Attached to the core 
are eight filaments that extend into the cytoplasm (cytoplasmic filaments, CFs), and a basket-like structure that extends into the nucleus. Nucleoporins (nups) that comprise these asymmetric structures are found exclusively on one side of the NPC. mRNA export involves a complex set of interactions that occur on CFs.

A key event during mRNA export is dissociation of protein components from mRNPs, which is thought to contribute to export directionality. This remodeling is mediated by Dbp5 (Lund and Guthrie 2005; Tran et al. 2007), a highly conserved member of the DEAD-box protein (DBP) family of related ATPases (>20 in both yeast and metazoan cells) (for review, see Cordin et al. 2006; Linder 2008). Many DBPs are able to denature short double-stranded regions of RNA in vitro, and some can remodel mRNA-protein complexes by removing bound proteins (Tran et al. 2007; for review, see Jankowsky 2011).

Dbp5 is the DBP that plays a central role in mRNA export. It was identified initially through a genetic screen in Saccharomyces cerevisiae aimed at identifying mRNA export factors and was called Rat8 (ribonucleic acid transport) (Snay-Hodge et al. 1998). In yeast cells carrying temperature-sensitive (ts) alleles of $R A T 8 / D B P 5$, poly $(\mathrm{A})^{+}$ RNA accumulates rapidly in nuclei upon a shift to $37^{\circ} \mathrm{C}$. Dbp5 interacts with two proteins located at or near the NPC CFs: Nup159 and Gle1 (Hodge et al. 1999; Schmitt et al. 1999; Strahm et al. 1999). This has led to working models wherein Dbp5 is proposed to function late during mRNA export by catalyzing the remodeling of mRNPs (Cole et al. 2002; Cole and Scarcelli 2006; Tran and Wente 2006; Stewart 2007, 2010).

Gle1 acts in concert with the soluble phosphoinositide inositol hexakisphosphate $\left(\mathrm{IP}_{6}\right)$ to stimulate ATP hydrolysis by Dbp5 at the NPC, precisely at the location where mRNPs exit the NPC channel (York et al. 1999; AlcazarRoman et al. 2006; Weirich et al. 2006; Wente and Rout 2010). This converts Dbp5-ATP to Dbp5-ADP, thereby driving dissociation of protein from the mRNP (Tran et al. 2007; Noble et al. 2011). There is evidence that the mRNA export receptor Mex67 and the RNA-binding protein Nab2, both of which accompany the mRNP through NPCs, are removed from mRNPs by Dbp5 acting at the CFs (Lund and Guthrie 2005; Tran et al. 2007). Nab2 may function as an adapter for Mex67 (Carmody et al. 2010; Iglesias et al. 2010), which mediates the interaction of mRNPs with NPCs (Segref et al. 1997; Strawn et al. 2001; Terry and Wente 2007). Thus, removal of Nab2 by Dbp5 would promote release of the mRNP into the cytoplasm. Overall, mRNA export is mediated by the interaction of Dbp5 with Nup159, Gle1, ATP, ADP, and mRNP.

Although Dbp5 binds to the N-terminal domain (NTD) of Nup159, this interaction is not essential (Del Priore et al. 1997). Yeast strains harboring the nup $159 \Delta N$ or nup159 $9^{E E-V I}$ allele, encoding Nup159 lacking or mutated in its Dbp5-binding site, display severe mRNA export and temperature-sensitive growth defects (Hodge et al. 1999; Weirich et al. 2004). However, overexpression of DBP5 completely suppresses these defects.
To gain a mechanistic understanding of the role Dbp5 plays in the mRNA export process, we set out to define the order of Dbp5-dependent events at the NPC. To this end, we used DBP5 point mutants defective for ATP binding, ATP hydrolysis, and RNA binding. The two unable to bind RNA are also dominant-negative (DN). By investigating both the mutant in vivo phenotypes and the biochemical properties of the altered proteins in vitro, critical steps in the Dbp5 cycle during export were defined and their order was revealed. In addition, we examined the in vivo dynamics of mutant and wild-type Dbp5 in yeast and human cells. Fluorescence recovery after photobleaching (FRAP) experiments in yeast reveal that Dbp5 has a very dynamic association with NPCs, while live-cell analysis of mRNP trafficking in human cells showed that the R372G mutant of hDbp5, analogous to the DN yeast mutant R369G, also has a DN effect on mRNA export and causes accumulation of single mRNPs at the nuclear periphery. We found that ATP binding and ATP hydrolysis are required for efficient association of Dbp5 with NPCs. Furthermore, RNA binding to Dbp5 is required for efficient release of Dbp5 from Gle1, but is independent from docking of Dbp5 at Nup159. From this we propose a model wherein Dbp5 interacts with Nup159 (Nup214 in human cells) and is then transferred to Gle1. Gle1-IP 6 activates Dbp5 ATPase activity and positions it to remodel mRNPs during NPC exit. Interaction with Glel is limiting for mRNA export and can be independent of Nup159. Analysis of the R369G mutant suggests that its dominant phenotype reflects competition for Gle1. Furthermore, once bound to Gle1 at the NPC, R369G appears to occupy these sites longer than wild-type Dbp5 because it cannot bind mRNPs. In a companion study (Noble et al. 2011), we show that Nup159 catalyzes dissociation of ADP from Dbp5, and present a model wherein we propose that an individual Dbp5 polypeptide is able to mediate more than one round of mRNP remodeling through cyclical interactions with its binding partners.

\section{Results}

Isolation and characterization of S. cerevisiae DBP5 mutants affecting ATP binding, ATP hydrolysis, and RNA binding

During mRNA export, Dbp5 has multiple binding partners: Nup159, Gle1, RNA (e.g., mRNP), ATP, and ADP (resulting from hydrolysis of ATP). To determine the order of events involving Dbp5 at the NPC, we constructed DBP5 mutants affecting DBP motifs I (K144Q), II (E240Q), and VI (R426Q) (Fig. 1A). These residues were selected based on prior studies of human Dbp5 and other DBPs. Motifs I (AxxGxGKT) and II (DExD) are the Walker $A$ and $B$ boxes present in all DBPs and most NTPases (for review, see Jankowsky 2011). In other DBPs, motif I is required for ATP binding, motifs I and II are required for ATPase activity, and motif VI (IHRGRGGRxG) plays an important role in both ATPase activity and RNA binding (Pause et al. 1994; Linder 2008). Expressed as the only form of Dbp5, none of these mutants were viable (Supplemental Fig. S1). 
Hodge et al.

A

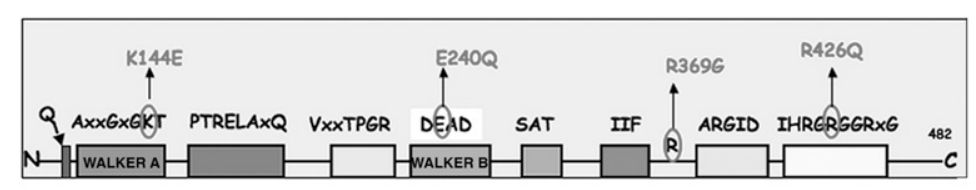

C

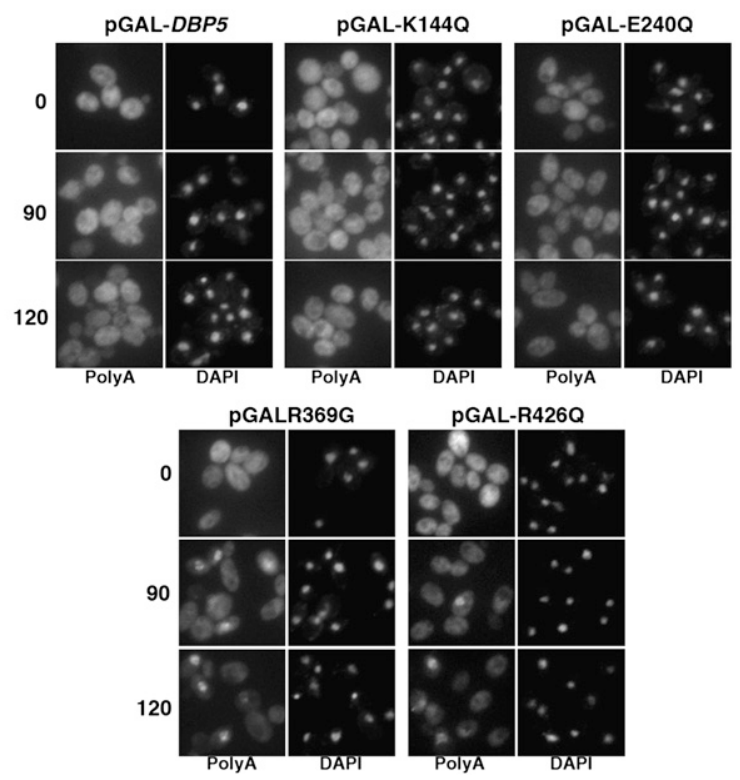

B
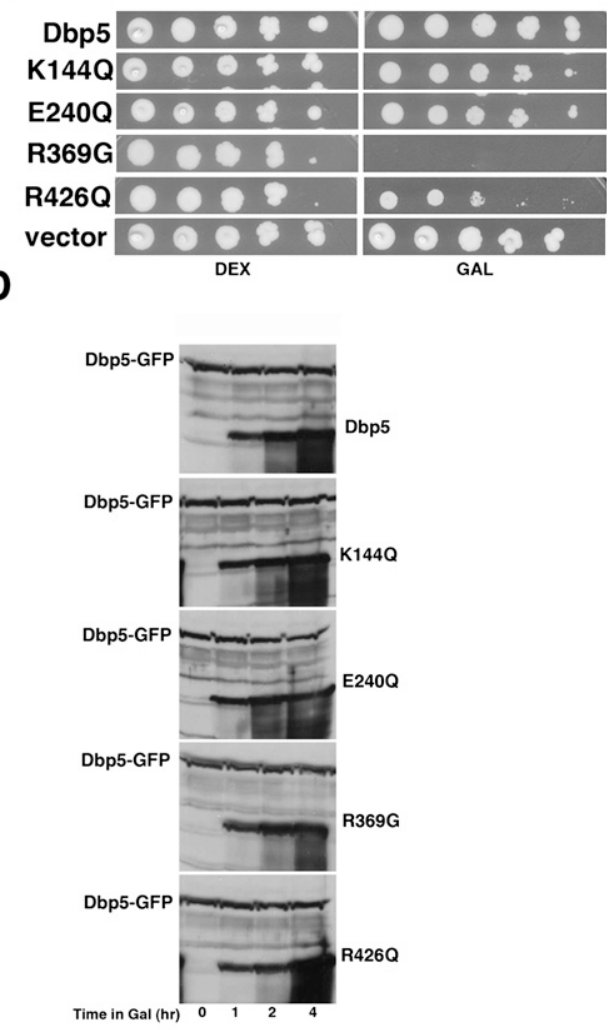

Figure 1. Effect of overexpressed wild-type and altered Dbp5 proteins on growth and mRNA export. $(A)$ Organization of Dbp5, location of conserved DBP motifs, and location of mutations shown. (B) Effect of inducing expression of high levels of wild-type or altered Dbp5 proteins on yeast cell growth. Serial dilutions of wild-type yeast cells containing GAL1 plasmids encoding wild-type or altered Dbp5 were plated on plates containing dex or gal and incubated for $5 \mathrm{~d}$ at $30^{\circ} \mathrm{C}$. $(C)$ Coding regions for wild-type and altered Dbp5 were placed under control of the GAL1 promoter. Expression of wild-type or altered proteins was induced by transfer of cells from $2 \%$ raf to $2 \%$ gal and poly $(\mathrm{A})^{+}$RNA distribution detected by fluorescent in situ hybridization (FISH). (D) Western blot for wild-type and altered Dbp5 proteins. Cells were grown overnight in raf and then incubated in medium containing either $2 \%$ dex or $2 \%$ gal for indicated times. All cells express Dbp5-GFP from the genomic DBP5 locus, with its position also shown.

Each mutant was also placed under control of the GAL1 promoter in wild-type cells to permit induced high-level expression by growth in galactose (gal) medium. Figure 1B compares growth on dextrose (dex) and gal plates for wildtype cells carrying each of these GAL1 plasmids. The K144Q and E240Q mutants were not DN. In contrast, expression of R426Q inhibited growth. From a genetic screen to identify DN mutants of Dbp5, we identified R369G as a strong DN allele (also shown in Fig. 1B). Next, we examined the effect of these alleles on mRNA export in the presence of wild-type Dbp5. Consistent with their being recessive lethal alleles, coexpression of K144Q or E240Q with wild-type Dbp5 had no effect, whereas R369G and R426Q induction led to nuclear accumulation of poly $(\mathrm{A})^{+}$RNA (Fig. 1C). The export defect was detected within $60 \mathrm{~min}$ of a shift from raffinose (raf) to gal medium, and was seen in all cells within $3 \mathrm{~h}$. These defects are not due to differences in protein levels, as all Dbp5 variants accumulated with approximately the same kinetics and to much higher levels than wild-type Dbp5-GFP expressed from the DBP5 locus (Fig. 1D). The results suggest that the
DN phenotypes reflect defects in the Dbp5 enzymatic cycle during mRNA export.

GFP-tagged versions of the altered proteins were used to determine subcellular localization. GFP fusions to R369G and R426Q retained the DN phenotypes of the untagged forms, although with some reduction in the strength of growth inhibition (data not shown). Wild-type Dbp5-GFP, R369G-GFP, and R426Q-GFP were readily detected at the nuclear rim (Fig. 2A), reflecting NPC association. In contrast, K144Q-GFP and E240Q-GFP were predominantly cytoplasmic with little or no NE signal detected (Fig. 2A). To further test whether the K144Q or E240Q proteins had any ability to associate with NPCs, we deleted genomic DBP5 and expressed wild-type Dbp5 from a gal-inducible promoter. Following depletion of wild-type Dbp5 by shifting cells from gal to dex, E240Q-GFP, but not K144Q-GFP, became detectable at NPCs, but the signal was considerably weaker than that for wild-type Dbp5-GFP (Fig. 2B). Western blots showing depletion of wild-type Dbp5 are in Supplemental Figure S2. Taken together, the contrasting effects on NPC 
A

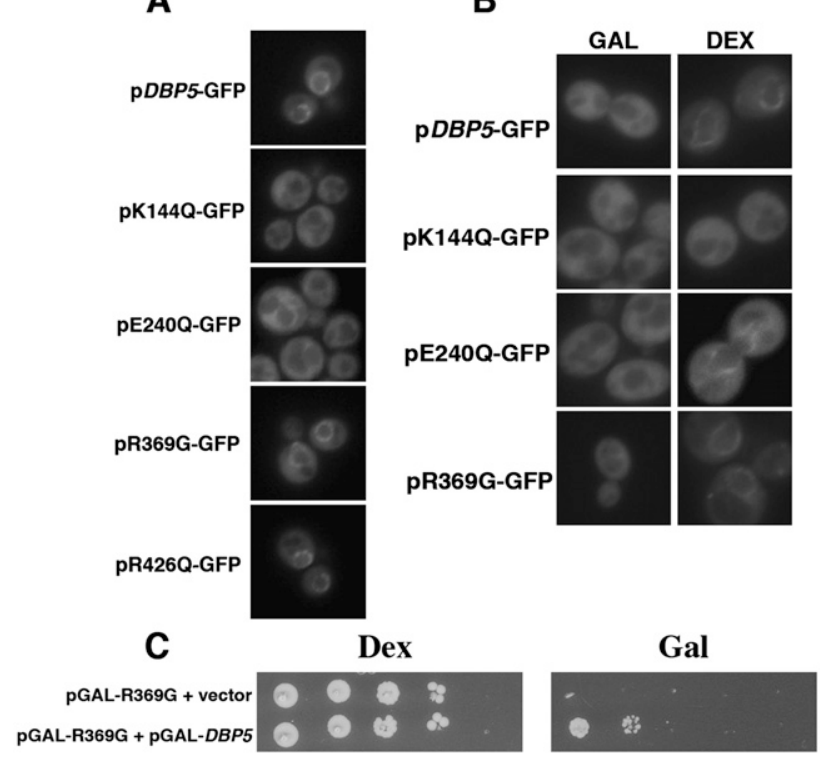

Figure 2. (A) Localization of GFP fusions to wild-type and altered Dbp5 proteins. Cells expressing GFP-tagged proteins from centromeric plasmids were visualized by fluorescence microscopy. Although the R369G mutant inhibits growth, cells grow, albeit slowly, when R369G is expressed from a centromeric plasmid. (B) Effect of depleting wild-type Dbp5 on localization of wild-type and variant Dbp5s. Cells expressing wild-type Dbp5 only from the GAL1 promoter were grown overnight (18 h) in medium containing gal $(2 \%)$ or dex $(2 \%)$. Expression was induced by transfer of cells from medium containing $2 \%$ raf to medium containing $2 \%$ gal and was imaged after $4 \mathrm{~h}$. $(C)$ Induction of wild-type Dbp5 reduces growth inhibition caused by R369G. Wild-type Dbp5 was expressed from a GAL1 promoter. Serial dilutions of cells were plated on either dex- or gal-containing plates for $3 \mathrm{~d}$.

association indicated distinct defects in the mRNA export mechanism for the K144Q and E240Q versus the DN R369G and R426Q proteins.

A DN phenotype generally reflects competition between wild-type and DN mutant proteins for limiting binding sites or substrate. We tested whether overexpression of wild-type Dbp5 could suppress the DN R369G phenotype. Using cells expressing wild-type Dbp5 from its genomic locus and either R369G or both R369G and wild-type Dbp5 under control of the GAL1 promoter, we found that increasing the ratio of wild-type Dbp5 to R369G reduced growth inhibition by R369G (Fig. 2C). Western blots indicate that approximately equal amounts of R369G and wild-type Dbp5 were highly expressed. In the experiments in Figure 2, both wild-type Dbp5 and R369G were untagged, since tags reduce the functionality of wild-type Dbp5 and the DN phenotypes of R369G. In a parallel experiment, we analyzed expression of tagged constructs (Supplemental Fig. S3) to distinguish genomic Dbp5 from gal-induced Dbp5 and R369G. Tagged wildtype Dbp5 and R369G were each expressed at severalfold the level of Dbp5-GFP produced from its genomic locus (Supplemental Fig. S3). We conclude that R369G inhibition occurs by a competitive mechanism. The most likely limiting components are Dbp5 interaction partners at the NPC: Nup159 and/or Gle1.

\section{Biochemical properties of defective Dbp5 proteins}

Our previous work demonstrated that ATP hydrolysis by Dbp5 is stimulated by RNA and is further increased by coactivators Gle1 and $\mathrm{IP}_{6}$ (Alcazar-Roman et al. 2006). To determine whether the altered dbp5 proteins had perturbed biochemical activities, each was expressed in bacteria and purified for in vitro biochemical assays. ATPase assays were conducted in the presence of RNA and either Gle1 or Gle1-IP 6 , and results were normalized to the activity measured for wild-type Dbp5 (Fig. 3A). Consistent with alteration of essential motifs needed for ATP binding and hydrolysis, the K144Q, E240Q, and R426Q proteins showed minimal ATPase activity alone, and this activity was not stimulated by Gle1-IP 6 (Fig. 3A). Importantly, the R369G protein retained ATPase activity with $\sim 60 \%$ the wild-type level of Gle1-IP ${ }_{6}$-dependent ATP hydrolysis (Fig. 3A). Interestingly, Gle1 addition without $\mathrm{IP}_{6}$ reduced R369G ATPase activity, whereas Gle1 stimulates wild-type Dbp5 even in the absence of $\mathrm{IP}_{6}$ (Fig. 3A). This suggested that R369G is impacted differently by Gle1.

Next, we performed ATP- and RNA-binding assays to assess substrate and ligand binding. ATP binding was analyzed quantitatively by in vitro UV cross-linking of ${ }^{32} \mathrm{P}-\alpha$-ATP $(10 \mathrm{nM})$ to purified protein in the presence or absence of RNA (Fig. 3B). Substitution of the critical lysine in the Walker A motif (K144Q) abolished ATP binding, which was not restored by addition of RNA (Fig. 3B). In contrast, the E240Q Walker B mutation enhanced ATP binding to a level $\sim 2.5$ times that of wild-type Dbp5. The R369G and R426Q proteins alone each had reduced ATP binding. We conclude that loss of ATP binding or ATPase activity by Dbp5 is not sufficient to cause a DN growth phenotype, but either mutation results in a loss of function and inhibits NPC binding.

To determine whether the R369G ATPase activity was RNA-dependent, ATPase assays were conducted in the presence of increasing RNA concentrations (Fig. 3C). Whereas wild-type Dbp5 showed an increase in the initial velocity of ATP hydrolysis at $1 \mu \mathrm{M}$ RNA, the ATPase activity of R369G was not stimulated at any RNA concentration tested. This suggested that the R369G protein could not bind RNA. To directly examine RNA interaction, filter-binding assays were performed using recombinant proteins and a $5^{\prime}{ }^{32} \mathrm{P}$-labeled oligo $(\mathrm{A})_{25}$ RNA molecule. Both the E240Q and K144Q proteins retained the ability to associate with RNA (Fig. 3D). Consistent with the inability of RNA to stimulate ATP hydrolysis by R369G, R369G had severely reduced ability to bind RNA. R426Q also showed decreased RNA binding. Of note, in the human Dbp5-RNA crystal structure, the residues corresponding by sequence alignment to yeast R369 and R426 are both positioned in the RNA-binding pocket /von Moeller et al. 2009). While R426 is within a very highly conserved motif shared by all DBPs, the region surrounding R369G is not part of any of the conserved motifs and 
Hodge et al.

A

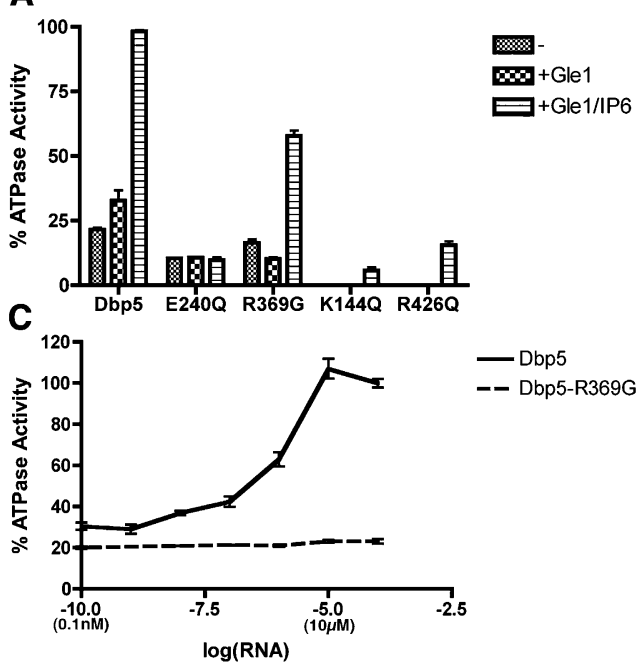

B

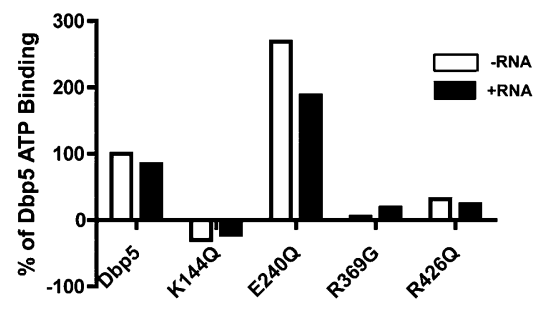

D

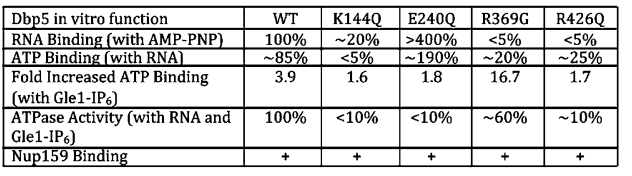

Figure 3. Biochemical analyses of Dbp5 and dbp5 variants. (A) Initial velocities of ATP hydrolysis were assayed and reported as a percentage of wild-type Dbp5 activity from the average of three replicates. All assays are in the presence of $1 \mu \mathrm{M}$ RNA with $250 \mathrm{nM}$ the respective Dbp5. (B) ATP binding was measured by in vitro UV cross-linking and reported as a percentage of ATP binding by wild-type Dbp5 in the presence and absence of $1 \mu \mathrm{M}$ RNA. (C) Stimulation of Dbp5 or R369G ATPase activity by RNA was measured with increasing concentrations of oligo(A $)_{25}$ RNA, all with $500 \mathrm{nM}$ respective Dbp5, $250 \mathrm{nM}$ Gle1, and $100 \mathrm{nM} \mathrm{IP}_{6}$. (D) Summary of in vitro biochemical properties of wild-type (WT) and variant Dbp5 proteins. Assays were conducted with purified recombinant proteins for RNA by filter binding (binding affinity percent relative to wild-type), ATP binding with RNA (B), fold increased ATP binding with Gle1-IP 6 (Fig. $5 F)$, ATPase activity with RNA and Gle1-IP $6(A)$, and Nup159 binding by soluble binding assays; plus sign $(+)$ indicates normal binding.

shows moderate variation among them. However, comparison of this region of several yeast DBPs and representative DBPs from several other organisms indicates that R369 is the most highly conserved residue in this region (Supplemental Fig. S4). In the structure of a complex between a synthetic $\mathrm{U}_{10}$ RNA and human DDX19 (orthologous to yeast Dbp5), the guanidinium group of R372 can form two hydrogen bonds with the phosphodiester backbone of the RNA (Collins et al. 2009).

Because the sites for hDbp5 binding to Nup214 and RNA overlap (von Moeller et al. 2009), we directly tested the altered Dbp5 proteins for in vitro interaction with the NTD of Nup159. In soluble binding assays with purified recombinant proteins (see the Materials and Methods), all interacted similarly to wild type (Fig. 3D). We also assayed for the ability of wild-type Dbp5 versus R369G protein to enhance $\mathrm{IP}_{6}$ binding by Gle1 and found that both were effective to approximately the same extent (Supplemental Fig. S5A). This indicated that R369G binding to Gle1 is not altered compared with wild type. This was verified directly by soluble binding assays with purified recombinant proteins (Supplemental Fig. S5B). Taken together, this suggested that, for R369G, the specific lack of RNA binding underlies its DN inhibition of growth and mRNA export.

\section{Genetic requirements for the R369G DN growth phenotype}

Because the R369G protein retains the ability to bind and hydrolyze ATP and associates with the NPC in vivo, we hypothesized that the R369G DN phenotype reflects competition between R369G and wild-type Dbp5 for binding Nup159 and/or Gle1. To examine this, we tested the ability of R369G to inhibit growth of strains with mutations in genes encoding Nups located asymmetrically on the cytoplasmic face of the NPC. We used nup159 $\Delta N$, which lacks its Dbp5-binding site (Del Priore et al. 1997; Hodge et al. 1999; Strahm et al. 1999), and nup42s. Nup42 directly interacts with Gle1 and is linked to Gle1 function (Murphy and Wente 1996; Hodge et al. 1999; Strahm et al. 1999). We also tested a gfd1s mutant due to the known functional and physical links between Gfd1 and Dbp5 (Estruch et al. 2005), Gle1 (Suntharalingam et al. 2004), and Nab 2 (Suntharalingam et al. 2004; Zheng et al. 2010). In all cases, the expression of R369G inhibited growth to the same extent as in wild-type cells (Fig. 4A), demonstrating that none of these factors is required for R369G's DN effect.

To further test for links between Dbp5, Gle1, and Nup159, we constructed a set of double mutants wherein dbp5 contained both the R369G mutation and point mutations that substantially reduce Dbp5's ability to bind Gle1 (Dossani et al. 2009) or Nup159 (Noble et al. 2011). For mutants affecting the Dbp5-Gle1 interaction, we used $d b p 5-E 323 K$ and $d b p 5-E 473 K$. Both are viable, and E473K is temperature-sensitive (Dossani et al. 2009). Strikingly, the R369G/E323K mutant was not DN, and the R369G/E473K mutant was considerably less DN than R369G (Fig. 4B). To probe the Dbp5-Nup159 interaction, we used a R256D/R259D allele encoding a Dbp5 protein that does not interact with Nup159 and is not detected at the nuclear periphery (Noble et al. 2011). The triple R256D/R259D/R369G mutant retained the DN growth phenotype of R369G (Fig. 4B). Finally, we examined the 
A

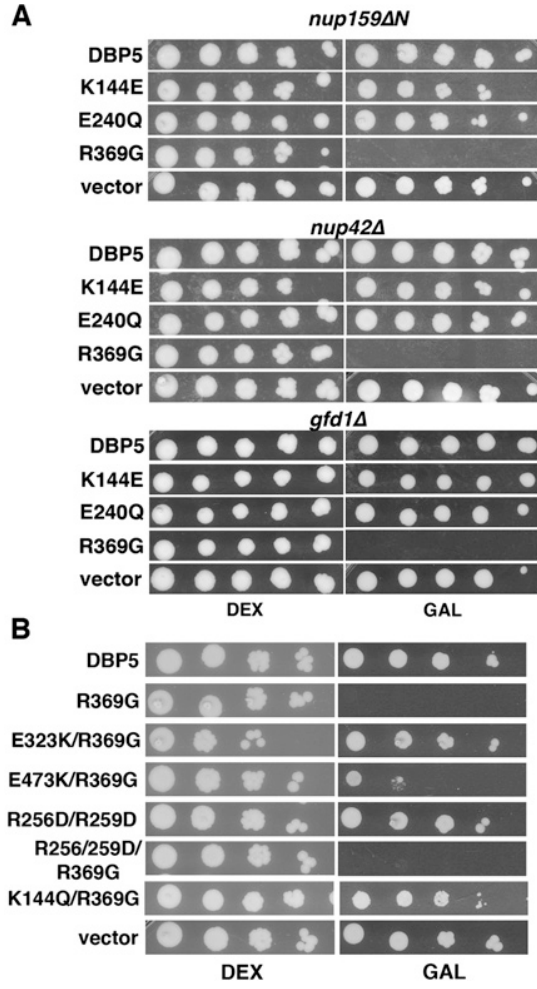

Figure 4. (A) Comparing the effects of expressing wild-type or mutant DBP5 on growth of yeast cells carrying mutations affecting Nup159, Nup42, or Gfd1. Cells were plated on dex- or gal-containing plates. All mutant strains express wild-type Dbp5 from the genomic DBP5 locus. (B) Effect of combining mutations affecting Dbp5's interactions with ATP, Nup159, or Gle1 on the DN growth inhibitory phenotype of R369G.

effect of combining R369G with K144E, which prevents binding to ATP and association of Dbp5 with NPCs. In comparison with R369G, the double mutant had a severely reduced DN effect on growth of wild-type cells. All of the variant Dbp5 proteins were induced to approximately the same level (Supplemental Fig. S6). We conclude that the strong DN phenotype of R369G does not require the NTD of Nup159 and is dependent on the interaction between Dbp5 and both Gle1 and ATP.

\section{Increasing Gle1 levels in vitro rescues inhibition} of wild-type Dbp5 activity by R369G

To define the mechanistic basis for the Gle1-dependent DN activity of the R369G allele, we conducted a series of in vitro assays. First, we tested whether the R369G protein altered the ability of Gle1-IP 6 to activate wild-type Dbp5 ATPase activity. The velocity of ATP hydrolysis for wild-type Dbp5 was measured in the presence of RNA, Gle1-IP $\mathrm{I}_{6}$ and increasing levels of recombinant purified R369G or K144Q at 0.2-5 times the molar Gle1 level (Fig. 5A,B). Assays were normalized for the ATPase activity from R369G or K144Q alone under the same conditions. Strikingly, we found that the R369G protein dramatically reduced the Gle1-IP ${ }_{6}$-stimulated ATPase activity of wild-type Dbp5 in a concentrationdependent manner (Fig. 5A). Importantly, the K144Q protein had no effect on wild-type Dbp5 activity (Fig. 5B), consistent with K144Q not being DN.

These results supported our conclusion that the R369G protein is competing with wild-type Dbp5 for association with Gle1 and ATPase activation. A prediction of this model is that increasing amounts of Glel could overcome the DN effect of R369G and restore Dbp5 ATPase activity. To test this, ATPase assays were conducted as in Figure 5A but with increasing levels of Gle1-IP 6 (up to a threefold molar excess). In agreement with our predictions, the reduced ATPase activity of wild-type Dbp5 was reversed by addition of increasing Gle1- $\mathrm{IP}_{6}$ levels (Fig. 5C). This activity was not mediated by altering $\mathrm{IP}_{6}$ binding to Gle1, as both wild-type Dbp5 and the R369G protein enhanced $\mathrm{IP}_{6}$ binding to similar extents (Supplemental Fig. S5). This was also consistent with the lack of a requirement for $\mathrm{IP}_{6}$ production (ipk1s cells) for R369G to display DN behavior (data not shown). To investigate the impact of increased Gle1 on R369G in vivo, Gle1 was overexpressed in cells expressing wild-type Dbp5 and R369G. Growth was partially rescued (Fig. 5D). Overexpression was monitored by Western blotting (Supplemental Fig. S7). Importantly, although wild-type Dbp5-GFP is not readily detectable at the NPCs in nup1594N cells, R369G-GFP was still detected at the nuclear periphery (Fig. 5E). Thus, the DN phenotype of R369G is due to competition for Gle1, leading to impairment of the wild-type Dbp5 ATPase cycle at the NPC. Moreover, this effect is not dependent on Nup159-NTD.

To further probe for changes in Gle1-Dbp5 interaction mediated by R369G, we measured the level of ATP binding by Dbp5 in the presence of Gle1-IP 6 . Using an in vitro UV cross-linking assay and recombinant purified proteins, we found that Gle1-IP 6 enhanced the level of ATP bound by $\sim 3.5$-fold (Fig. 5F). For the R369G protein, addition of Gle1-IP 6 increased $\sim 16$-fold the amount of bound ATP (Fig. 5F). Interestingly, the increase in ATP binding for R369G was specific for the presence of Gle1$\mathrm{IP}_{6}$, as R369G bound little ATP in the absence of Gle1-IP 6 (Fig. 3B). The basal level of ATP binding by the K144Q, E240Q, or R426Q proteins was not altered by addition of Gle1-IP ${ }_{6}$. This indicated a specific link between Gle1-IP 6 action and facilitation of ATP binding to R369G. Overall, we propose that the DN phenotype reflects competition for occupancy of Gle1 at NPCs by R369G, effectively decreasing the capacity of Gle1-IP 6 to bind and activate wild-type Dbp5. Furthermore, the data in Figure 5E suggest that R369G may occupy Gle1-binding sites longer than wild-type Dbp5, possibly because it cannot bind RNA and proceed productively through the cycle.

\section{Association of Dbp5 with NPCs is ATP-dependent and highly dynamic}

Because the K144Q and E240Q proteins are defective in ATP binding and/or ATPase activity and show little or no in vivo localization to NPCs, we investigated whether the interactions between Dbp5 and NPCs require any particular in vivo nucleotide-bound state. Notably, based on in vitro studies of the human protein (von Moeller et al. 2009), Dbp5 bound to ATP is expected to have the lowest affinity for 
A
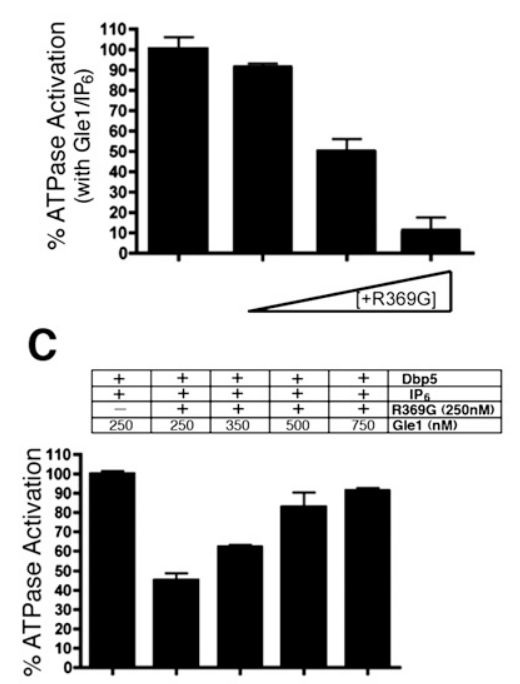

E

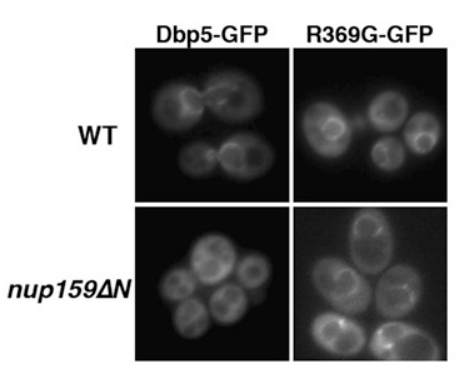

B

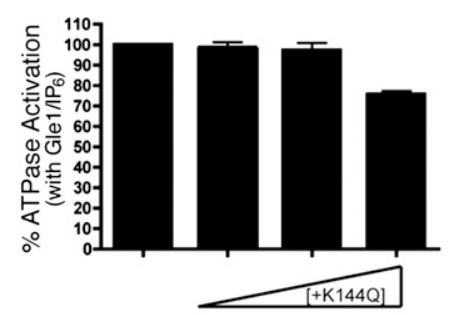

D

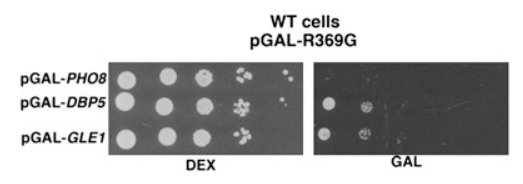

$\mathbf{F}$

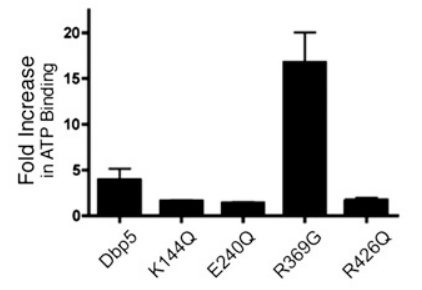

Figure 5. In vitro ATPase and ATP-binding assays measuring the DN effect of R369G on wild-type Dbp5. (A) ATPase assays were conducted with 500 nM Dbp5, $250 \mathrm{nM}$ Gle1, $100 \mathrm{nM} \mathrm{IP}$, and increasing amounts of R369G $150 \mathrm{nM}, 250 \mathrm{nM}$, and $1.25 \mu \mathrm{M})$. (B) ATPase assays were conducted as in $A$ but with $\mathrm{K} 144 \mathrm{Q}$ protein. $(C)$ "Rescue" assays were conducted as in $A$ with R369G protein (250 $\mathrm{nM}$ ) and increasing amounts of Gle1-IP 6 complex at 1.4-fold, twofold, and threefold excess of that used in $A$. The percent ATPase activation by Gle1$\mathrm{IP}_{6}$ was calculated by subtracting measured initial velocities $\left(\mathrm{V}_{\mathrm{i}}\right)$ for ATP hydrolysis in the presence of R369G or K144Q minus $\mathrm{V}_{\mathrm{i}}$ for Dbp5 with Gle1-IP 6 . $(D)$ Effect of high-level expression of Dbp5 or Gle1 on growth of wild-type (WT) cells expressing R369G. Serial dilutions of cells carrying plasmids with DBP5 or GLE1 under control of the GAL1 promoter were plated on plates containing dex (left) or gal (right). (E) Wild-type (WT) or nup1594N cells expressing Dbp5-GFP or R369G-GFP were grown overnight and analyzed by fluorescence microscopy. (F) Fold activation of ATP binding by Dbp5 in the presence of Gle1-IP $6(1 \mu \mathrm{M} / 400 \mathrm{nM})$ was determined using in vitro UV cross-linking assays as above (Fig. 3B).
Nup159, with Dbp5-ADP and Dbp5-APO having greater affinity. If ATP binding is necessary for efficient NPC association in vivo, cellular depletion of ATP should trigger loss of wild-type Dbp5 from NPCs. Indeed, when cells were treated for 10 min with sodium azide and 2-deoxy-glucose to deplete ATP, wild-type Dbp5-GFP was not detected at the nuclear rim/NPCs (Fig. 6A). In marked contrast, under these conditions, R369G-GFP was detected at the nuclear $\mathrm{rim} / \mathrm{NPCs}$. We conclude that, in vivo, NPC association of wild-type Dbp5 is dependent on its nucleotide-bound state, whereas R369G association is independent of ATP.

To examine the dynamics of the Dbp5 interaction with NPCs, we analyzed FRAP in cells expressing Dbp5-GFP from the DBP5 locus. Recovery of fluorescence at NPCs was rapid, with half recovery occurring in $\sim 0.8 \mathrm{sec}$ (Fig. $6 \mathrm{~B})$. One possible concern in these studies is that yeast NPCs are mobile within the NE (Belgareh and Doye 1997; Bucci and Wente 1997). This contrasts with NPCs of metazoan cells, which are largely immobile due to their interactions with the nuclear lamina (Lenz-Bohme et al. 1997; Liu et al. 2000). If NPCs with bound Dbp5-GFP were to diffuse within the NE into the bleached area, there would be ambiguity about whether recovery occurred through a Dbp5 dissociation/replacement mechanism or by diffusion within the NE of NPCs to which unbleached Dbp5-GFP was bound. When a small spot on the nuclear rim of cells expressing Nup82-GFP was bleached, we saw no recovery of fluorescence after $30 \mathrm{sec}$ (Fig. 6B), a period substantially longer than the observed period for recovery of Dbp5-GFP after photobleaching. In this experiment, Dbp5-GFP and Nup82-GFP were the only forms of the respective protein present and were expressed from their normal loci. We also compared FRAP of R369G-GFP with Dbp5-GFP, with each expressed from a centromeric plasmid. The Dbp5-GFP fusion is fully functional, as it covers a dbp5-null allele (Hodge et al. 1999). Tagging R369G with GFP slightly compromised its DN effect on growth (data not shown). Recovery of fluorescence for Dbp5-R369G was also rapid and approximately the same as that of wild-type Dbp5 (Fig. 6C). This is consistent with Dbp5R369G functioning as a competitive rather than noncompetitive inhibitor of wild-type Dbp5. Although the data in Figure 6, B and C, represent one FRAP analysis for each strain examined, $>30$ separate analyses were conducted with each, with approximately the same results.

\section{Human Dbp5-R372G inhibits mRNA export in mammalian cells, and mRNPs accumulate at the nuclear periphery}

To extend these studies to mammalian cells, we constructed mutants in human Dbp5 that are equivalent to 
A

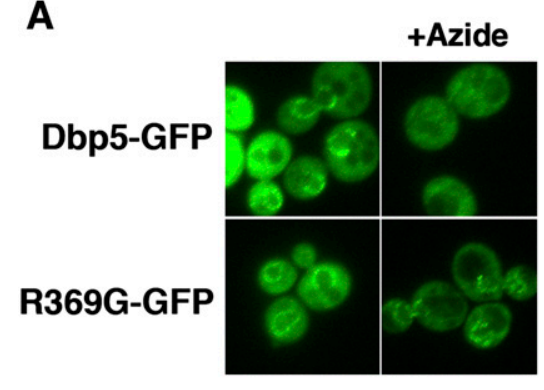

B
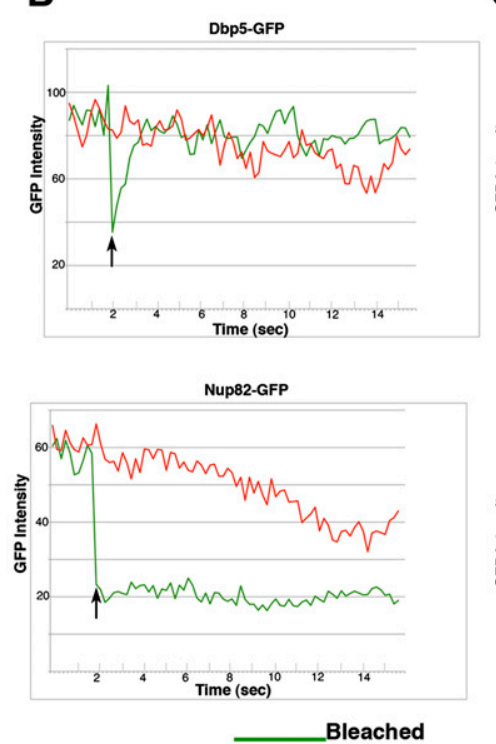

C
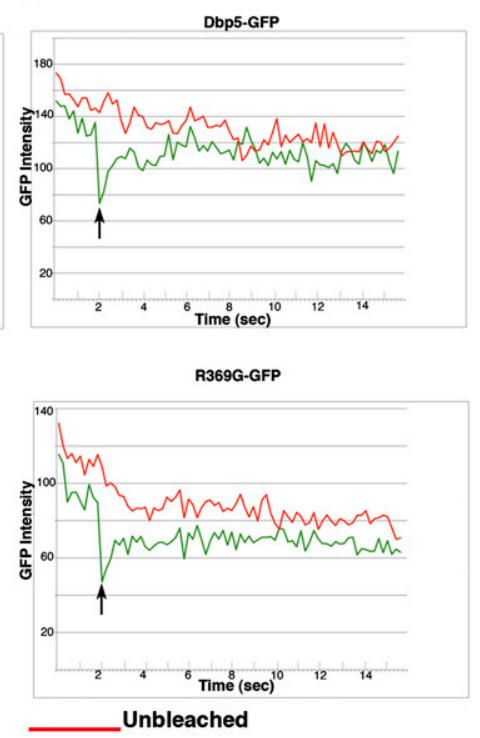

Figure 6. Association of Dbp5 with NPCs is ATP-dependent and dynamic. (A) Wild-type cells expressing Dbp5-GFP or R369G-GFP were visualized by fluorescence microscopy before and $10 \mathrm{~min}$ after addition of sodium azide $(10 \mathrm{mM})$ and 2-deoxy glucose (10 $\mathrm{mM})$. (B) FRAP analysis was performed on wild-type cells expressing Dbp5-GFP or Nup82-GFP from their genomic loci. $(C)$ GFP-tagged proteins (wild-type and R369G) were expressed from centromeric plasmids in wild-type cells under control of the DBP5 promoter. FRAP was performed on the brightest cells. The arrows in $B$ and $C$ indicate the lowest levels to which the signal dropped immediately after photobleaching. The green line in each panel is the bleached sample, and the red line is a control region of the same cell that was not subjected to photobleaching. Each panel in $B$ and $C$ represents a single FRAP analysis. In each case, $>30$ separate FRAP analyses were performed, with little difference among them and one representative shown.

the yeast mutants R369G (human R372G) and E240Q (human E242Q). After transfection of mammalian U20S cells, the distribution of poly $(\mathrm{A})^{+}$mRNA was examined by RNA fluorescence in situ hybridization (FISH). Cells continue to express wild-type Dbp5 from the genomic locus. mRNA is normally detected in both nucleus and cytoplasm, and this was observed for both wild-type hDbp5 (Fig. 7A) and the E242Q mutant (data not shown). In contrast, and consistent with the yeast DN R369G mutant phenotype, mRNAs in cells expressing hDbp5R372G cells were confined to the nuclear compartment and showed increased accumulation in nuclear speckles (Fig. 7A). This indicates that hDbp5-R372G recapitulates the DN effect on mRNPs export of yeast R369G.

We then analyzed the effect of R372G on the distribution of individual mRNPs in living cells using fluorescence microscopy. To visualize individual mRNPs, we used two constructs employed previously (Mor et al. 2010): one in which the mRNA is generated without splicing (Mini-Dys), and one that requires splicing $\left(1^{1} / 2-\right.$ Mini-Dys+intron mRNA). These mRNAs are engineered to contain multiple sites in their 3' untranslated regions (UTRs) to which the MS2 phage coat protein can bind. The location of individual mRNPs can be observed by coexpressing a YFP fusion to the MS2 coat protein (YFP-MS2). A normal nucleocytoplasmic distribution of these mRNPs was seen in untransfected human U2OS cells (or in cells transfected with a plasmid encoding hDbp5) (data not shown), whereas the mRNPs were retained in the nucleus in cells expressing hDbp5 R372G (Fig. 7B). To quantify the inhibitory effect of hDbp5-R372G on mRNA export, we counted the number of mRNPs in the nucleus and the cytoplasm (Fig. 7C), confirming the effect of hDbp5R372G on mRNA export. Imaging individual mRNPs in cells over time has shown that nuclear mRNPs are typically not detected as anchored to the NE but are predominantly dynamic in the nucleoplasm (Supplemental Fig. S8; Mor et al. 2010). Interestingly, in R372G-expressing cells, an increase in mRNPs anchored to or near the NE was observed (Fig. 7D,E; Supplemental Figs. S8A, S7B; Supplemental Movies S1, S2), while the dynamics of most intranuclear mRNPs were not perturbed (Supplemental Fig. S8A). This analysis indicates that mRNPs in cells expressing hDbp5R372G are targeted to the nuclear periphery, yet translocation to the cytoplasm is inhibited. Taken together, these results show that impairment of the interaction between Gle1-IP 6 and Dbp5 blocks late mRNA export steps in both yeast and human cells.

\section{Discussion}

The studies presented here are directed at defining the sequence of events at NPCs in which Dbp5 participates during mRNA export. During the export cycle, Dbp5 interacts with Nup159, RNA (in the form of mRNP), and Gle1-IP ${ }_{6}$ as well as with ATP and ADP. By using mutants that impact these interactions, we defined critical steps in the cycle.

First, Dbp5's ability to bind and hydrolyze ATP is important for its interaction with NPCs, but binding RNA is not. This conclusion is supported by several lines 
A

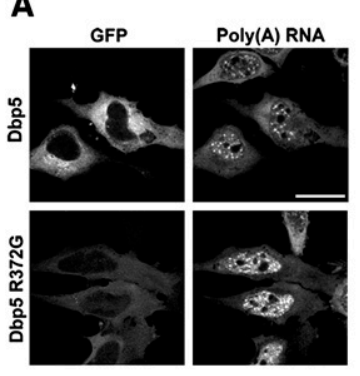

C

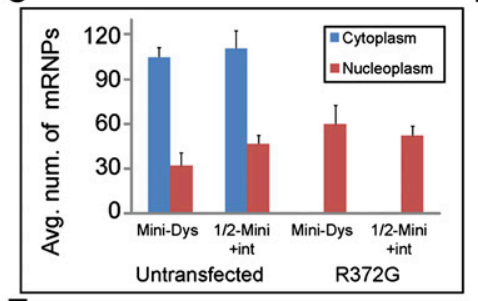

D

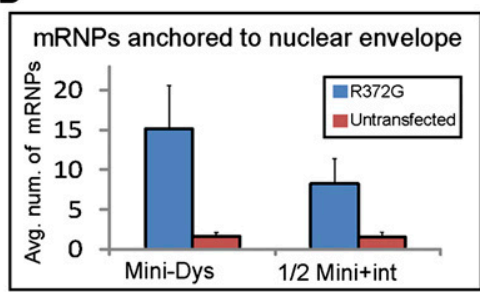

E

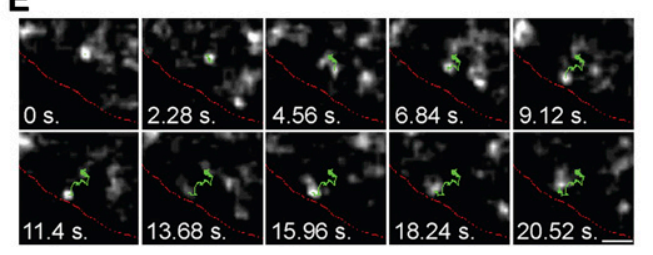

Figure 7. The effect of hDbp5 R372G on mRNA export. (A) FISH was performed to localize poly $(\mathrm{A})^{+} \mathrm{RNA}$ in cells expressing only wild-type Dbp5 or wild-type Dbp5 and R372G. Bar, $25 \mu \mathrm{m}$. (B) Cells expressing 1/2-Mini-Dys+intron-MS2 mRNA (Mor et al. 2010) were induced to transcribe, and mRNPs were visualized by using YFPMS2 protein that binds to the $3^{\prime}$ UTR of these mRNAs (green). (Left) Untransfected cell showing mRNPs in the cytoplasm and nucleoplasm (top), compared with a hDbp5 R372G-epxpressing cell containing nuclear-confined mRNPs only (bottom). (Right) Analyzed images depicting cytoplasmic mRNPs are shown in cyan, and nuclear RNPs are shown in red. Bar, $10 \mu \mathrm{m} .(C)$ The number of cytoplasmic versus nucleoplasmic YFP-MS2-tagged mRNPs in two cell lines was counted. Bars show standard deviation, $N=709$ (mini-Dys-MS2 mRNPs) and 1045 (1/2-Mini-Dys+intron-MS2 mRNPs). (D) The number of NE-anchored mRNPs was measured in untransfected and Dbp5 R372G-expressing cells. Bars show standard deviation, $N=80$ (Mini-Dys-MS2 mRNPs) and 64 (1/2-Mini-Dys+intron-MS2 mRNPs). (E) Frames from a movie showing mRNP movement in a Dbp5 R372G-expressing cell in which the mRNP becomes transiently anchored at the NE. Track of mRNP movement is shown in green, and the position of the NE is shown in red. Bar, $1 \mu \mathrm{m}$. of evidence from different $d b p 5$ point mutants. The K144Q protein, which is altered in the Walker A box, does not bind ATP (Fig. 3C), is not detected at NPCs even when wild-type Dbp5 is absent (Fig. 2B), and cannot support cell growth (Supplemental Fig. S1). Consistent with this apparent requirement that Dbp5 bind ATP to allow NPC localization, wild-type Dbp5 is not detected at NPCs when ATP is depleted by treating cells with sodium azide and 2-deoxy glucose (Fig. 6A), agents that together prevent ATP regeneration. Furthermore, the $d b p 5$-E240Q mutant alters the Walker B box and, like K144Q, is a recessive lethal (Supplemental Fig. S1). E240Q has minimal in vitro ATPase activity that is not stimulated by Gle1-IP 6 (Fig. 3A). Like K144Q, the E240Q protein is not present at NPCs in wild-type cells (Fig. 2A), even when overexpressed. In contrast to K144Q, however, a low level of E240Q-GFP at NPCs is observed when wild-type Dbp5 is depleted (Fig. 2B). This indicates that E240Q has some ability to interact with NPCs, most likely because it can bind ATP, but its interaction with NPCs is inefficient.

We found that the ability to bind RNA is not required for Dbp5 to interact with NPCs. The R369G and R426Q mutants are readily detected at NPCs (Fig. 2A), even though they are defective for RNA binding (Fig. 3D). Both also have DN effects on growth and mRNA export (Fig. 1). This epistatic relationship further indicates that the ATP-binding step precedes the RNA-binding step, which is consistent with biochemical analysis of Dbp5RNA binding: ATP-bound Dbp5 has a greater affinity for RNA than ADP-bound (Weirich et al. 2006; Tran et al. 2007).
Second, mRNA export requires that Dbp5 interact with Gle1; however, as indicated previously, the interaction with Nup159 is not essential. Several nup159 mutants, including nup159 $\Delta \mathrm{N}$, have been described that have lost the ability to bind Dbp5 but remain viable (Hodge et al. 1999; Weirich et al. 2004). Similarly, the DN R369G phenotype is not diminished in nup1594N cells (Fig. 4A). Because R369G but not wild-type Dbp5 can be detected at NPCs even when the NTD of Nup159 is absent (Fig. 5E), the signal for wild-type Dbp5 reflects primarily its binding to Nup159, whereas the signal for R369G reflects its occupancy of both Nup159- and Gle1-binding sites. The DN phenotypes reflect competitive inhibition of mRNA export by R369G, since the DN effects were reduced when wild-type Dbp5 or Gle1 was expressed at a high level in cells expressing R369G (Fig. 5D). This reflects competition by Dbp5 and R369G for Gle1, and demonstrates that the Gle1-Dbp5 interaction is critical and therefore likely a key limiting step in mRNA export.

Third, the inability to bind RNA impedes the cycle at the Gle1 step and inhibits mRNP translocation through NPCs. The DN phenotypes for the yeast R369G and human R372G mutants provide key insights into this step. R369G binds Nup159 and Gle1 and, since it retains ATPase activity, can also be in both the ADP- and ATPbound states. However, Nup159 binding is not required because a $d b p 5-R 256 \mathrm{D} / \mathrm{R} 259 \mathrm{D} / \mathrm{R} 369 \mathrm{G}$ mutant that likely lacks both Nup159 and RNA binding is still DN. On the other hand, binding to Glel is essential, since changes that altered Dbp5's interaction with Gle1 eliminated or reduced the R369G DN effect ( $d b p 5-\mathrm{E} 323 \mathrm{~K} / \mathrm{R} 369 \mathrm{G}$, $d b p 5$-E473K/ R369G) (Fig. 4B). The fact that R369G cannot bind RNA, 
inhibits wild-type activity in vitro by limiting Gle1 (Fig. $5 \mathrm{~A}, \mathrm{C}$ ), and is localized at the NE in nup $159 \Delta \mathrm{N}$ cells (Fig. $5 \mathrm{E})$ provides evidence for RNA binding facilitating release of Dbp5 from Gle1.

The human R372G mutant also had a negative effect on mRNA export (Fig. 7A,B), resulting in poly $(\mathrm{A})^{+}$mRNA accumulation in nuclear speckles. Using the mammalian cell system for live-cell imaging, we directly monitored individual mRNPs in cells expressing the DN hDbp5R372. Not surprisingly, expression of hDbp5-R372G increases the level of mRNPs in nuclei and inhibits mRNA export (Fig. 7). Importantly, there is also a dramatic increase ( $\sim 10$-fold) in the number of mRNPs located at the nuclear periphery, most likely at NPCs, and these mRNPs are transiently immobile.

To date, only one mRNA has been monitored at the electron microscopy level for export directionality and mRNP composition: The Balbiani ring mRNP from Chironomus tentans passes through NPCs with its 5' end leading (Mehlin et al. 1992). However, it is not known whether this is a general mechanism for mRNA export. The mRNPs we analyzed are localized by visualizing the YFP-MS2 protein bound to the 3' UTR, and thus the $3^{\prime}$ end of the mRNP might still be nuclear, whereas the $5^{\prime}$ end might have entered the NPC channel and reached the CFs. Overall, the mRNPs in the R372G cells are blocked at a stage where their productive interaction with wildtype Dbp5-Gle1 is required.

Although Dbp5 is abundant in the cytoplasm and is readily detected at NPCs, Dbp5 undergoes nucleocytoplasmic shuttling (Hodge et al. 1999) and has both genetic and physical interactions with the transcription machinery (Estruch and Cole 2003). Thus, it is possible that yeast Dbp5 associates with mRNPs first in the nucleus and accompanies them to and through the NPC, with Dbp5 associating with CFs at the time of remodeling. The only reported case in which Dbp5 is detected associated with nuclear mRNA/mRNP is the Balbiani ring mRNPs from C. tentans (Zhao et al. 2002). To date, there are no data supporting an association between yeast Dbp5 and mRNPs in the nucleus. Our finding here that R369G, which does not bind mRNA, still localizes at NPCs demonstrates that Dbp5 does not need to arrive at NPCs with an mRNP to interact with Gle1. Moreover, because hDbp5's binding sites for RNA and Nup214 overlap (von Moeller et al. 2009), if Dbp5 is bound to an exiting mRNP, the initial interaction at the NPC for Dbp5 is likely with Gle1, such that Dbp5 does not disassociate from the mRNP before remodeling is executed.

Combining the results from the in vivo and in vitro studies presented here with findings obtained previously (for review, see Stewart 2010) and in an accompanying study (Noble et al. 2011) allows us to propose a detailed model for the Dbp5 cycle at the NPC. We propose that individual Dbp5 polypeptides go through multiple cycles of ATP binding, ATP hydrolysis, and ADP release, along with remodeling of mRNP, before being replaced by another Dbp5. During this process, Dbp5 interacts alternately with Nup159 and Gle1. The Nup159 interaction serves to release ADP from those Dbp5 molecules that have become ADP-bound through hydrolysis of ATP in conjunction with mRNP remodeling (Noble et al. 2011), and also facilitates its interaction with Glel. It is not known when during the cycle Dbp5 becomes bound to ATP. As the intracellular concentration of ATP is high $>1$ mM) (Ozalp et al. 2010), Dbp5 might bind ATP soon after dissociation of ADP. However, because Gle1-IP 6 promotes ATP binding in vitro (Noble et al. 2011), Dbp5 might remain in the apo form until it moves from Nup159 to Gle1. The Dbp5-Nup159 interaction could facilitate the functionally critical interaction between Dbp5 and Gle1-IP, ${ }_{6}$ although several experiments indicate that Dbp5 binding to Nup159 is not essential for export (Hodge et al. 1999; Weirich et al. 2004; Noble et al. 2011). Moreover, competition for Gle1 by R369G does not require Nup159. Once bound to ATP and Gle1-IP ${ }_{6}$, interaction with the mRNP is enabled and ATP is hydrolyzed. Through this sequence of interactions, the conformational change associated with the conversion of Dbp5-ATP to Dbp5-ADP is harnessed to mediate mRNP remodeling and the release of mRNA-bound proteins. The entire process positions Dbp5 to hydrolyze ATP precisely at the site where mRNPs exit the NPC for release into the cytoplasm. Following this sequence of events, Dbp5-ADP either enters another round of this cycle or dissociates. What determines which of these happens might be stochastic, but other factors could be involved. This model is developed thoroughly in the accompanying study (Noble et al. 2011).

How many remodeling cycles a Dbp5 molecule goes through on average before dissociating from the NPC is not known. Two groups measured the time taken for a reporter mRNP to be translocated through an NPC and released into the cytoplasm, and found the time to be $\sim 0.2$ sec (Grunwald and Singer 2010) and $<0.5 \mathrm{sec}$ (Mor et al. 2010). The transcripts examined by Mor et al. (2010) were larger than those examined in the other study, and this may explain the differences in transport times measured. Whether mRNPs in yeast are transported with the same kinetics is not known, but it is likely to be relatively similar. Based on our FRAP experiments, Dbp5 spends, on average, $\sim 0.8 \mathrm{sec}$ associated with NPCs, which is consistent with one NPC-associated Dbp5 mediating a limited number of mRNP remodeling events.

Although the role of Nup159 in this cycle is not essential, ADP cannot be efficiently released from Dbp5 at NPCs without the Nup159-NTD (Noble et al. 2011), and this might prevent a single Dbp5 molecule from participating in multiple enzymatic cycles at an NPC. Without Nup159 binding, far fewer Dbp5 molecules would proceed through another cycle. Consequently, in nup $159 \Delta \mathrm{N}$ cells, fewer binding sites on Gle1 might be occupied by Dbp5 at any one time, explaining the dramatically reduced signal for Dbp5-GFP at NPCs in nup $159 \Delta N$ cells. In these cells, ADP could possibly be released from Dbp5 through the action of an as-yet-unidentified cytoplasmic Dbp5-ADP exchange or release factor. Because Dbp5 and its activation by Gle1-IP 6 are also important for translation termination (Gross et al. 2007; Bolger et al. 2008), it is highly likely that there is another factor besides Nup159 that normally mediates release of ADP from Dbp5-ADP generated during translation termination. Other genetic experiments 
support these conclusions. Overexpression of Dbp5 sup-

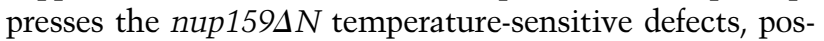
sibly by providing sufficient Dbp5-ATP to permit normal mRNA export and growth in the absence of the ADP release activity of Nup159. As shown in the accompanying study (Noble et al. 2011), Dbp5-R256D/R259D has a greater ability to release ADP than does wild-type Dbp5, and therefore does not require Nup159's NTD for ADP release.

Several important questions about the mechanism of mRNA export remain for future study. We do not know whether there is coordination among Dbp5s bound to multiple Nup159s at the same NPC. We do not know how many polypeptides are removed from a given mRNP during export, how long this process takes, and to what extent this is dependent on the length of the RNA. Although the data presented above are consistent with a single molecule of Dbp5 mediating the export of a single mRNP, more precise studies will be needed to address this definitively. These are challenging questions that are not amenable to in vitro studies. Therefore, answering them is likely to require advances in our ability to visualize the details of mRNA export and dissociation of protein from mRNP at the single-molecule level.

\section{Materials and methods}

\section{Plasmids and yeast strains}

Yeast strains and plasmids used are listed in Supplemental Tables S1 and S2. All strains were grown and media prepared using standard methods (Sambrook and Russell 2001). DBP5 point mutants were made using the QuikChange Site-Directed Mutagenesis kit (Stratagene no. 200519). Oligonucleotide sequences are listed in Supplemental Table S3. Growth assays were performed as described (Hodge et al. 2010). For growth assays comparing growth on dex plates versus gal plates, cells were grown overnight in medium containing $2 \%$ raf prior to the growth assay.

\section{Cell culture}

HeLa cells were cultured in complete medium (DME; Invitrogen) supplemented with $10 \%$ FBS at $37^{\circ} \mathrm{C}$ in $5 \% \mathrm{CO}_{2}$. Human U2OS cells stably expressing Mini-Dys-MS2 or 1/2-Mini-Dys-MS2+intron (Mor et al. 2010) were maintained in low-glucose Dulbecco's modified Eagle's medium (DMEM) (Beit Haemek) containing 10\% fetal bovine serum (FBS) (HyClone Laboratories). These cells expressed YFP-MS2 from a stably integrated plasmid. Transient transfections of mCherry-hDbp5 constructs were performed by electroporation (1-5 $\mu$ g of DNA; Gene Pulser Xcell, Bio-Rad) or FuGENE 6 (Roche). Transcription was activated with Ponasterone A $(10 \mu \mathrm{M})$ for $3 \mathrm{~h}$ prior to live-cell imaging.

\section{Microscopy}

Yeast live-cell microscopy was performed with a Nikon TE2000-E microscope (Nikon 100× Plan Apochromat oil objective, NA 1.4), Orca-ER CCD camera (Hamamatsu), and Volocity software, version 5.3.2 (Perkin Elmer). For HeLa cells (Fig. 7A), imaging was conducted with a Leica TCS SP5 laser-scanning confocal microscope (100× immersion oil lens, NA 1.47; Leica Microsystems). Optical sections were acquired and reconstructed into a threedimensional (3D) projection using Leica LAS AF software (Leica Microsystems). For U2OS cells (Fig. 7B,E), wide-field fluorescence images were obtained using the cell^ $\mathrm{R}$ system based on an Olympus IX81 fully motorized inverted microscope $(60 \times$ PlanApo objective, 1.42 NA; $100 \times, 1.40 \mathrm{NA}$ ) fitted with an Orca-AG CCD camera (Hamamatsu) driven by the cell^ $\mathrm{R}$ software. For time-lapse imaging, cells were plated on glass-bottomed tissue culture plates (MatTek) in medium containing $10 \% \mathrm{FBS}$ at $37^{\circ} \mathrm{C}$ and imaged with an on-scope incubator including temperature and $\mathrm{CO}_{2}$ control (Life Imaging Services) and a motorized stage (Scan IM, Märzhäuser). Movies were deconvolved using Huygens Essential II with timeseries option (Scientific Volume Imaging, Hilversum). Counting of mRNPs and tracking of mRNP movement was performed with the Imaris software (Bitplane).

FRAP studies were performed on a Zeiss LSM 510 scanning confocal microscope using the 488-nm line of an argon laser at 0.6 laser power and a $63 \times$ Plan Apochromat oil objective (NA 1.4). To acquire FRAP images, 10 prebleach and 70 post-bleach images were collected $(512 \times 50$ pixels, one iteration). The bleach event was a single pulse for $25 \mathrm{msec}$ at $100 \%$ laser power with a spot size of $0.96 \mu \mathrm{m}$ located on the NE.

\section{FISH}

To localize poly $(\mathrm{A})^{+}$RNA in yeast cells, we performed FISH as described (Cole et al. 2002). For induction of expression of wildtype or mutant $D B P 5$, cells were grown overnight in medium containing $2 \%$ raf and shifted to medium containing $2 \%$ gal for the times shown. To localize poly $(\mathrm{A})^{+}$RNA in HeLa cells, cells were fixed and processed as described (Watkins et al. 1998) for hybridization in buffer containing $0.5 \mu \mathrm{g} / \mu \mathrm{L}$ tRNA, $0.5 \mu \mathrm{g} / \mu \mathrm{L}$ ssDNA, and $1 \mathrm{ng} / \mu \mathrm{L}$ Oligo-dT-Cy3.

\section{Western blotting}

Crude cell lysates were prepared by a method adapted from Yaffe and Schatz (1984). Briefly, cells were harvested, washed with water, lysed in $1.85 \mathrm{M}$ sodium hydroxide and $7.4 \% \beta$-mercaptoethanol, and incubated for $10 \mathrm{~min}$ on ice. An equal volume of $50 \%$ trichloroacetic acid was added and incubated for $10 \mathrm{~min}$ on ice, and precipitated protein was collected by centrifugation. Samples were washed with $500 \mu \mathrm{L}$ of $1 \mathrm{M}$ Tris base and resuspended in SDS sample buffer (Laemmli 1970). Equal amounts of protein from each extract were separated by electrophoresis on $10 \%$ Bio-Rad precast Tris-HCl polyacrylamide gels (Bio-Rad no. 161-1155). Dbp5 was visualized with an anti-Dbp5 Ab (DM35) raised against the Dbp5 NTD (Snay-Hodge et al. 1998) or anti-Glel raised against MBPGle1 (Bolger et al. 2008).

\section{In vitro ATPase assays}

ATP hydrolysis assays were conducted using an $\mathrm{NADH}^{+}$enzyme-coupled absorbance assay as described previously (AlcazarRoman et al. 2010). Briefly, standard ATPase reactions were assembled with Dbp5 or indicated variant in 10 mM HEPES $/ \mathrm{pH}$ 7.5), $45 \mathrm{mM} \mathrm{NaCl}, 3 \mathrm{mM} \mathrm{MgCl}_{2}$, and $10 \%$ glycerol with, where indicated, Gle1, $100 \mathrm{nM} \mathrm{IP}_{6}$ (Sigma Chemical Co.), and oligo(A) 25-mer RNA in the presence of $1 \mathrm{mM}$ ATP. Competition assays with R369G or K144Q Dbp5 proteins were conducted with increasing amounts of $\mathrm{R} 369 \mathrm{G}$ or $\mathrm{K} 144 \mathrm{Q}$ protein to ATPase reactions with Dbp5, Gle1, $\mathrm{IP}_{6}$, and RNA. "Rescue" assays were conducted by adding R369G protein to reactions with wild-type Dbp5 and Gle1-IP 6 at 1.4-fold, twofold, and threefold excess. The percent ATPase activation in competition and rescue assays was calculated by subtracting measured initial velocities $\left(V_{i}\right)$ for ATP hydrolysis in the presence of R369G or K144Q, minus mutant protein alone from $\mathrm{V}_{\mathrm{i}}$ for Dbp5 with Gle1-IP ${ }_{6}$, minus Dbp5 alone. 
ATP, RNA, IP 6 , Gle1, and Nup159 in vitro binding assays

ATP binding was assessed as described (Solem et al. 2006). Briefly, $1 \mathrm{mM}$ wild-type or variant Dbp5 was incubated with 1 pM $\alpha-{ }^{32}$ PATP $(10 \mathrm{mCi} / \mathrm{mmol})$ (MP Biomedicals) in $10 \mathrm{mM}$ HEPES (pH 7.5), $45 \mathrm{mM} \mathrm{NaCl}, 3 \mathrm{mM} \mathrm{MgCl} 2$, and $10 \%$ glycerol for 10 min on ice. Oligo(A) ${ }_{25}$ RNA (Dharmacon), Gle1, and/or $\mathrm{IP}_{6}$ were added to a final concentration of $2 \mu \mathrm{M}, 1 \mu \mathrm{M}$, and $400 \mathrm{nM}$, respectively, as indicated. Cross-linking was conducted using a Stratalinker 1800 (Stratagene) for $10 \mathrm{~min}$ at $3 \mathrm{~cm}$ in BD Falcon UV transparent 96-well plates (no. 353261). Binding reactions were removed from the 96-well plates and incubated with excess, unlabeled ATP: $\mathrm{MgCl}_{2}$ and $50 \mathrm{U}$ of RNase I (Applied Biosystems) for $30 \mathrm{~min}$ at room temperature to reduce nonspecific binding and cleave-bound RNA. Resulting samples were resolved by denaturing (SDS) gel electrophoresis. Bound ATP was detected by autoradiography. The percent ATP binding was calculated as the ATP-bound intensity versus a non-cross-linked sample as a background control. Gle1-IP ${ }_{6}$-induced increase in ATP binding was calculated as fold increase in signal intensity with or without Gle1-IP. 6 . RNA binding (with AMP-PNP) was assayed by filter binding as described previously (Tran and Wente 2006), using a $5^{\prime}{ }^{32}$ P-labeled oligo(A) ${ }_{25}$ RNA. For Dbp5 interaction, soluble binding assays were conducted with bacterially expressed, recombinant Dbp5 and Nup159 proteins as described (Noble et al. 2011). Dbp5 enhancement of $\mathrm{IP}_{6}$ binding by Gle1 was conducted using a PEG precipitation assay as described (Alcazar-Roman et al. 2006). Direct Gle1 binding to wild-type and R369G Dbp5 was conducted using an established soluble binding assay (Alcazar-Roman et al. 2010).

\section{Acknowledgments}

We thank members of the Cole, Wente, and Shav-Tal laboratories for discussions. Support for this work was provided by grants from the NIH (GM33998 to C.N.C.; R37 GM51219 to S.R.W.; 1F32 GM075459 to E.J.T.; 1F31 HD061181 to K.N.N.; and 1F31 NS070431 and 5T32 CA119925 to A.F.W.), the European Research Council (to Y.S.T.), and the Israel Science Foundation (grant 250/06 to Y.S.T.). J.J.S. was supported by a training grant from the NIH (AR07576). Y.S.T. is the Jane Stern Lebell Family Fellow in Life Sciences at BIU.

\section{References}

Alcazar-Roman AR, Tran EJ, Guo S, Wente SR. 2006. Inositol hexakisphosphate and Glel activate the DEAD-box protein Dbp5 for nuclear mRNA export. Nat Cell Biol 8: 711-716.

Alcazar-Roman AR, Bolger TA, Wente SR. 2010. Control of mRNA export and translation termination by inositol hexakisphosphate requires specific interaction with Gle1. I Biol Chem 285: 16683-16692.

Belgareh N, Doye V. 1997. Dynamics of nuclear pore distribution in nucleoporin mutant yeast cells. J Cell Biol 136: 747759.

Bolger TA, Folkmann AW, Tran EJ, Wente SR. 2008. The mRNA export factor Glel and inositol hexakisphosphate regulate distinct stages of translation. Cell 134: 624-633.

Bucci M, Wente SR. 1997. In vivo dynamics of nuclear pore complexes in yeast. J Cell Biol 136: 1185-1199.

Carmody SR, Tran EJ, Apponi LH, Corbett AH, Wente SR. 2010. The mitogen-activated protein kinase Slt2 regulates nuclear retention of non-heat shock mRNAs during heat shockinduced stress. Mol Cell Biol 30: 5168-5179.

Cho EJ, Takagi T, Moore CR, Buratowski S. 1997. mRNA capping enzyme is recruited to the transcription complex by phosphorylation of the RNA polymerase II carboxyterminal domain. Genes Dev 11: 3319-3326.

Cole CN, Scarcelli JJ. 2006. Unravelling mRNA export. Nat Cell Biol 8: 645-647.

Cole CN, Heath CV, Hodge CA, Hammell CM, Amberg DC. 2002. Analysis of RNA export. Methods Enzymol 351: 568587.

Collins R, Karlberg T, Lehtiö L, Schütz P, van den Berg S, Dahlgren L-G, Hammarström M, Weigelt J, Schüler H. 2009. The DEXD/H-box RNA helicase DDX19 is regulated by an $\alpha$-helical switch. J Biol Chem 284: 10296-10300.

Cordin O, Banroques J, Tanner NK, Linder P. 2006. The DEADbox protein family of RNA helicases. Gene 367: 17-37.

D'Angelo MA, Hetzer MW. 2008. Structure, dynamics and function of nuclear pore complexes. Trends Cell Biol 18: 456-466.

Del Priore V, Heath C, Snay C, MacMillan A, Gorsch L, Dagher S, Cole C. 1997. A structure/function analysis of Rat7p/ Nup159p, an essential nucleoporin of Saccharomyces cerevisiae. J Cell Sci 110: 2987-2999.

Dossani ZY, Weirich CS, Erzberger JP, Berger JM, Weis K. 2009. Structure of the C-terminus of the mRNA export factor Dbp5 reveals the interaction surface for the ATPase activator Gle1. Proc Natl Acad Sci 106: 16251-16256.

Estruch F, Cole CN. 2003. An early function during transcription for the yeast mRNA export factor Dbp5p/Rat8p suggested by its genetic and physical interactions with transcription factor IIH components. Mol Biol Cell 14: 16641676.

Estruch F, Hodge CA, Rodriguez-Navarro S, Cole CN. 2005. Physical and genetic interactions link the yeast protein Zds1p with mRNA nuclear export. J Biol Chem 280: 96919697.

Gross T, Siepmann A, Sturm D, Windgassen M, Scarcelli JJ, Seedorf M, Cole CN, Krebber H. 2007. The DEAD-box RNA helicase Dbp5 functions in translation termination. Science 315: 646-649.

Grunwald D, Singer RH. 2010. In vivo imaging of labelled endogenous $\beta$-actin mRNA during nucleocytoplasmic transport. Nature 467: 604-607.

Hetzer MW, Wente SR. 2009. Border control at the nucleus: biogenesis and organization of the nuclear membrane and pore complexes. Dev Cell 17: 606-616.

Hodge CA, Colot HV, Stafford P, Cole CN. 1999. Rat8p/Dbp5p is a shuttling transport factor that interacts with Rat7p/ Nup159p and Glelp and suppresses the mRNA export defect of xpo1-1 cells. EMBO J 18: 5778-5788.

Hodge CA, Choudhary V, Wolyniak MJ, Scarcelli JJ, Schneiter R, Cole CN. 2010. Integral membrane proteins Brr6 and Apq12 link assembly of the nuclear pore complex to lipid homeostasis in the endoplasmic reticulum. J Cell Sci 123: 141151.

Iglesias N, Tutucci E, Gwizdek C, Vinciguerra P, Von Dach E, Corbett AH, Dargemont C, Stutz F. 2010. Ubiquitin-mediated mRNP dynamics and surveillance prior to budding yeast mRNA export. Genes Dev 24: 1927-1938.

Jankowsky E. 2011. RNA helicases at work: binding and rearranging. Trends Biochem Sci 36: 19-29.

Laemmli UK. 1970. Cleavage of structural proteins during the assembly of the head of bacteriophage T4. Nature 227: 680685.

Lenz-Bohme B, Wismar J, Fuchs S, Reifegerste R, Buchner E, Betz H, Schmitt B. 1997. Insertional mutation of the Drosophila nuclear lamin Dm0 gene results in defective nuclear envelopes, clustering of nuclear pore complexes, and accumulation of annulate lamellae. J Cell Biol 137: 1001-1016. 
Hodge et al.

Licatalosi DD, Darnell RB. 2010. RNA processing and its regulation: global insights into biological networks. Nat Rev Genet 11: 75-87.

Linder P. 2008. mRNA export: RNP remodeling by DEAD-box proteins. Curr Biol 18: R297-R299. doi: 10.1016/j.cub. 2008.02.027.

Liu J, Rolef Ben-Shahar T, Riemer D, Treinin M, Spann P, Weber K, Fire A, Gruenbaum Y. 2000. Essential roles for Caenorhabditis elegans lamin gene in nuclear organization, cell cycle progression, and spatial organization of nuclear pore complexes. Mol Biol Cell 11: 3937-3947.

Lund MK, Guthrie C. 2005. The DEAD-box protein Dbp5p is required to dissociate Mex67p from exported mRNPs at the nuclear rim. Mol Cell 20: 645-651.

Mehlin H, Daneholt B, Skoglund U. 1992. Translocation of a specific premessenger ribonucleoprotein particle through the nuclear pore studied with electron microscope tomography. Cell 69: 605-613.

Moore MJ, Proudfoot NJ. 2009. Pre-mRNA processing reaches back to transcription and ahead to translation. Cell 136: 688700.

Mor A, Suliman S, Ben-Yishay R, Yunger S, Brody Y, Shav-Tal Y. 2010. Dynamics of single mRNP nucleocytoplasmic transport and export through the nuclear pore in living cells. Nat Cell Biol 12: 543-552.

Murphy R, Wente SR. 1996. An RNA-export mediator with an essential nuclear export signal. Nature 383: 357-360.

Noble KN, Tran EJ, Alcázar-Roman AR, Hodge CA, Cole CN, Wente SR. 2011. The Dbp5 cycle at the nuclear pore complex during mRNA export II: nucleotide cycling and mRNP remodeling by Dbp5 are controlled by Nup159 and Gle1. Genes Dev (this issue). doi: 10.1101/gad.2040611.

Ozalp VC, Pedersen TR, Nielsen LJ, Olsen LF. 2010. Timeresolved measurements of intracellular ATP in the yeast Saccharomyces cerevisiae using a new type of nanobiosensor. J Biol Chem 285: 37579-37588.

Pandit S, Wang D, Fu XD. 2008. Functional integration of transcriptional and RNA processing machineries. Curr Opin Cell Biol 20: 260-265.

Pause A, Methot N, Svitkin Y, Merrick WC, Sonenberg N. 1994. Dominant negative mutants of mammalian translation initiation factor eIF-4A define a critical role for eIF-4F in capdependent and cap-independent initiation of translation. EMBO J 13: 1205-1215.

Perales R, Bentley D. 2009. 'Cotranscriptionality': the transcription elongation complex as a nexus for nuclear transactions. Mol Cell 36: 178-191.

Sambrook J, Russell DW. 2001. Molecular cloning: A laboratory manual. Cold Spring Harbor Laboratory Press, Cold Spring Harbor, NY.

Schmitt C, von Kobbe C, Bachi A, Pante N, Rodrigues JP, Boscheron C, Rigaut G, Wilm M, Seraphin B, Carmo-Fonseca M, et al. 1999. Dbp5, a DEAD-box protein required for mRNA export, is recruited to the cytoplasmic fibrils of nuclear pore complex via a conserved interaction with CAN/Nup159p. EMBO J 18: 4332-4347.

Segref A, Sharma K, Doye V, Hellwig A, Huber J, Luhrmann R, Hurt E. 1997. Mex67p, a novel factor for nuclear mRNA export, binds to both poly $(\mathrm{A})^{+}$RNA and nuclear pores. EMBO J 16: 3256-3271.

Snay-Hodge CA, Colot HV, Goldstein AL, Cole CN. 1998. Dbp5p/Rat8p is a yeast nuclear pore-associated DEAD-box protein essential for RNA export. EMBO J 17: 2663-2676.

Solem A, Zingler N, Pyle AM. 2006. A DEAD protein that activates intron self-splicing without unwinding RNA. Mol Cell 24: 611-617.
Stewart M. 2007. Ratcheting mRNA out of the nucleus. Mol Cell 25: 327-330.

Stewart M. 2010. Nuclear export of mRNA. Trends Biochem Sci 35: 609-617.

Strahm Y, Fahrenkrog B, Zenklusen D, Rychner E, Kantor J, Rosbach M, Stutz F. 1999. The RNA export factor Glelp is located on the cytoplasmic fibrils of the NPC and physically interacts with the FG-nucleoporin Riplp, the DEAD-box protein Rat8p/Dbp5p and a new protein Ymr 255p. EMBO I 18: $5761-5777$.

Strawn LA, Shen T, Wente SR. 2001. The GLFG regions of Nup116p and Nup100p serve as binding sites for both Kap95p and Mex67p at the nuclear pore complex. I Biol Chem 276: 6445-6452.

Suntharalingam M, Alcazar-Roman AR, Wente SR. 2004. Nuclear export of the yeast mRNA-binding protein Nab2 is linked to a direct interaction with Gfdl and to Glel function. I Biol Chem 279: 35384-35391.

Terry LJ, Wente SR. 2007. Nuclear mRNA export requires specific FG nucleoporins for translocation through the nuclear pore complex. I Cell Biol 178: 1121-1132.

Tran EJ, Wente SR. 2006. Dynamic nuclear pore complexes: life on the edge. Cell 125: 1041-1053.

Tran EJ, Zhou Y, Corbett AH, Wente SR. 2007. The DEAD-box protein Dbp5 controls mRNA export by triggering specific RNA:protein remodeling events. Mol Cell 28: 850-859.

von Moeller H, Basquin C, Conti E. 2009. The mRNA export protein DBP5 binds RNA and the cytoplasmic nucleoporin NUP214 in a mutually exclusive manner. Nat Struct Mol Biol 16: 247-254.

Watkins JL, Murphy R, Emtage JL, Wente SR. 1998. The human homologue of Saccharomyces cerevisiae Glelp is required for poly(A) ${ }^{+}$RNA export. Proc Natl Acad Sci 95: 6779-6784.

Weirich CS, Erzberger JP, Berger JM, Weis K. 2004. The $\mathrm{N}$-terminal domain of Nup159 forms a $\beta$-propeller that functions in mRNA export by tethering the helicase Dbp5 to the nuclear pore. Mol Cell 16: 749-760.

Weirich CS, Erzberger JP, Flick JS, Berger JM, Thorner J, Weis K. 2006. Activation of the DExD/H-box protein Dbp5 by the nuclear-pore protein Gle1 and its coactivator InsP6 is required for mRNA export. Nat Cell Biol 8: 668-676.

Wente SR, Rout MP. 2010. The nuclear pore complex and nuclear transport. Cold Spring Harb Perspect Biol 2: a000562. doi: 10.1101/cshperspect.a000562.

Yaffe MP, Schatz G. 1984. Two nuclear mutations that block mitochondrial protein import in yeast. Proc Natl Acad Sci 81: 4819-4823.

York JD, Odom AR, Murphy R, Ives EB, Wente SR. 1999. A phospholipase C-dependent inositol polyphosphate kinase pathway required for efficient messenger RNA export. Science 285: 96-100.

Zhao J, Jin SB, Bjorkroth B, Wieslander L, Daneholt B. 2002. The mRNA export factor Dbp5 is associated with Balbiani ring mRNP from gene to cytoplasm. EMBO J 21: 1177-1187.

Zheng C, Fasken MB, Marshall NJ, Brockmann C, Rubinson ME, Wente SR, Corbett AH, Stewart M. 2010. Structural basis for the function of the Saccharomyces cerevisiae Gfd1 protein in mRNA nuclear export. I Biol Chem 285: 2070420715.

Zhong XY, Wang P, Han J, Rosenfeld MG, Fu XD. 2009. SR proteins in vertical integration of gene expression from transcription to RNA processing to translation. Mol Cell 35: $1-10$. 


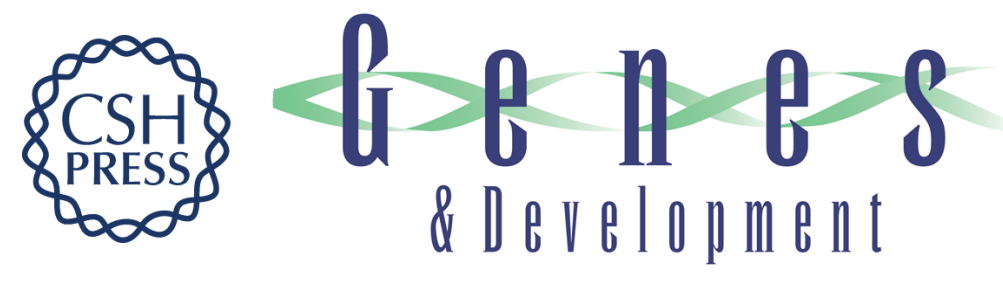

\section{The Dbp5 cycle at the nuclear pore complex during mRNA export I: dbp5 mutants with defects in RNA binding and ATP hydrolysis define key steps for Nup159 and Gle1}

Christine A. Hodge, Elizabeth J. Tran, Kristen N. Noble, et al.

Genes Dev. 2011, 25:

Access the most recent version at doi:10.1101/gad.2041611

\section{Supplemental http://genesdev.cshlp.org/content/suppl/2011/05/10/25.10.1052.DC1 \\ Material}

Related Content

Regulation of the Dbp5 ATPase cycle in mRNP remodeling at the nuclear pore: a lively new paradigm for DEAD-box proteins

Sarah Ledoux and Christine Guthrie

Genes Dev. June , 2011 25: 1109-1114

References

This article cites 59 articles, 30 of which can be accessed free at:

http://genesdev.cshlp.org/content/25/10/1052.full.html\#ref-list-1

Articles cited in:

http://genesdev.cshlp.org/content/25/10/1052.full.html\#related-urls

\section{License}

Email Alerting

Service

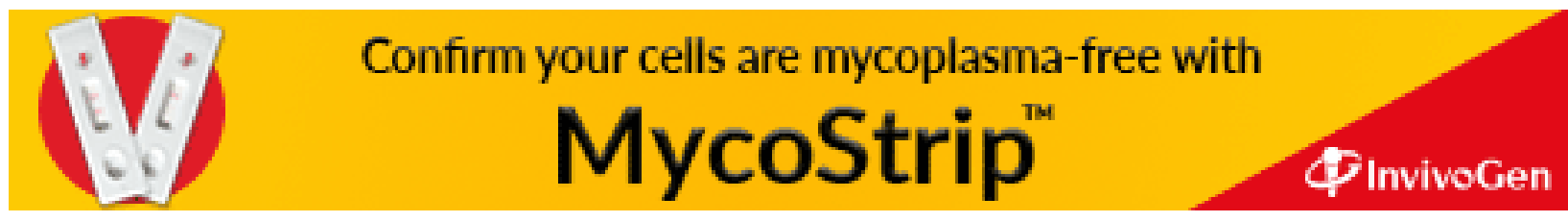

